\title{
11
}

\section{Model Calibration of a Large Urban Sewer System using Radar Precipitation Information}

Darko Joksimovic, Christine Hill, Greg Reilly, Adrien Comeau, Eric Tousignant and Daniel Jobin

This chapter describes the development and calibration of an XP SWMM Project Model of the City of Ottawa's major interceptor and collector sewers. The Project Model was developed to confirm the size and assist in the development of an operating strategy for the Somerset Wastewater Storage Facility (SWSF). Significant temporal and spatial variability of rainfall over the large West Nepean sewershed area precluded the calibration of the entire Project Model utilizing precipitation information from the area rain gauges alone. Rainfall data was developed for a virtual rain gauge network, which provided 5-minute rainfall volume estimates for each $1 \mathrm{~km}^{2}$ of the drainage area, utilizing data from the existing rain gauges and the weather radar information. Final Project Model calibration was performed using the flow data collected at six flow monitoring stations in the West Nepean portion of the collection system and the virtual rain gauge data averaged over the Project Model sub-catchment areas. In general, measured and modelled peak flows and event volumes matched well, with 17 out of 24 events having peak flows within the $15 \%$ envelope. Measured and modelled event volumes were within a $15 \%$ envelope for all 24 model calibrations. Rainfall estimates for the large West Nepean sewershed area based on radar imaging enabled the calibration of the Project Model, which would not have been possible using data obtained from the area rainfall gauges alone.

Joksimovic, D., C. Hill, G. Reilly, A. Comeau, E. Tousignant and D. Jobin. 2003. "Model Calibration of a Large Urban Sewer System using Radar Precipitation Information." Journal of Water Management Modeling R215-11. doi: 10.14796/JWMM.R215-11.

(C) CHI 2003 www.chijournal.org ISSN: 2292-6062 (Formerly in Practical Modeling of Urban Water Systems. ISBN: 0-9683681-7-4) 


\subsection{Introduction}

All urban drainage models require rainfall as input. The input can consist of rainfall intensities for one or several storms, used for model calibration or analysis of collection systems under extreme conditions, or a long-term continuous series of rainfall data for average performance analysis.

The performance requirements for CSO control in Ontario are based on long-term average values. In order to evaluate the average long-term performance, rainfall series (recorded or generated) for a large number of years are needed. Meteorological Service of Canada (formerly Atmospheric Environment Service or AES) of Environment Canada maintains a large number of rainfall recording stations, and the station records are typically used for continuous simulations of urban drainage systems in Canada. Long-term (hourly) rainfall record from the AES station closest to the modeled drainage system is usually selected, and used as input to estimate its average long-term performance. The stations are spaced anywhere from several kilometers to hundreds of kilometers apart. For model calibration purposes however, rainfall information at a much smaller scale is required. In order to capture the rainfall information needed for the operation of the collection system and treatment facilities, municipalities often install additional ran gauges. The rainfall data collected at these gauges is typically used to calibrate the models of the collection systems.

Depending on the collection area included in a particular model, point rainfall information from the rain gauges may or may not be sufficient for model calibration purposes, sizing of overflow control facilities in combined systems, and determination of the collection system operating strategies. Effects of both spatial (Schilling, 1984; Faures et al., 1995; Koren et al., 1999) and temporal (Ogden and Julien, 1993; Ball, 1994) distributions have been shown to be significant in runoff modeling.

In the City of Ottawa case presented in this chapter, an XP SWMM model of a large portion of the City's collection system (West Nepean) was calibrated initially using point precipitation data from three municipal rain gauges. The model was developed to confirm the size and assist in the development of an operating strategy for the Somerset Wastewater Storage Facility (SWSF). Early results of the calibration process indicated that significant spatial and temporal variability existed over the large catchment area being modeled, and that there was a need for better indication of the rainfall that occurred during the monitoring period. Given that flows from West Nepean sewershed area of the City of Ottawa collection system will be diverted to the SWSF under 
emergency conditions, the West Nepean area provides an important boundary condition in the system. Therefore, it was crucial that the calibration of that part of the Project Model be as accurate as possible.

In the following sections, the background for the Somerset Wastewater Storage Facility Project in the City of Ottawa is presented first, followed by the details on the development of the Project Model of the City of Ottawa collection system. Results of the initial calibrations of the West Nepean portion of the Project Model are covered next. The development of the radar precipitation data and the results of the final model calibration are described briefly. Following that, a summary of the project is presented along with the conclusions reached.

\subsection{Background}

The City of Ottawa's sanitary sewer system consists of local sewers and many large collector sewers. Three major interceptor sewers, the Ottawa Interceptor-Outfall Sewer, the Green Creek Collector, and the Orleans-Cumberland Interceptor, convey flows to the treatment plant, the Robert O. Pickard Environmental Centre (ROPEC). The SWSF was conceived to address the CSO discharges and wet weather flows in the Ottawa Interceptor-Outfall Sewer service area.

Figure 11.1 presents the locations of the collector sewers, the Ottawa Interceptor-Outfall Sewer and ROPEC. The Ottawa Interceptor-Outfall Sewer services the older portions of the City of Ottawa and contains most of the partially separated and combined areas within the City. It also conveys flows from the West Nepean Collector, as shown in Figure 11.1, which services approximately 3,200 ha. Land use within the West Nepean sewershed area is mostly residential. Approximately $71 \%$ of the serviced area is separated, $28 \%$ is partially separated, and $1 \%$ is combined.

Many of the large collector sewers which discharge into the Ottawa Interceptor-Outfall Sewer are equipped with regulating chambers which allow overflows to occur into the Ottawa River. Seven major float controlled regulators control the flows that can enter into the Ottawa Interceptor-Outfall Sewer from the collector sewers. In addition to the float controlled regulator chambers, there are also a significant number of uncontrolled regulator chambers.

System wide modeling conducted as part of the Wastewater System Operational Review Study concluded that approximately $82 \%$ of wet weather flows were being intercepted and received treatment at ROPEC. The City has 


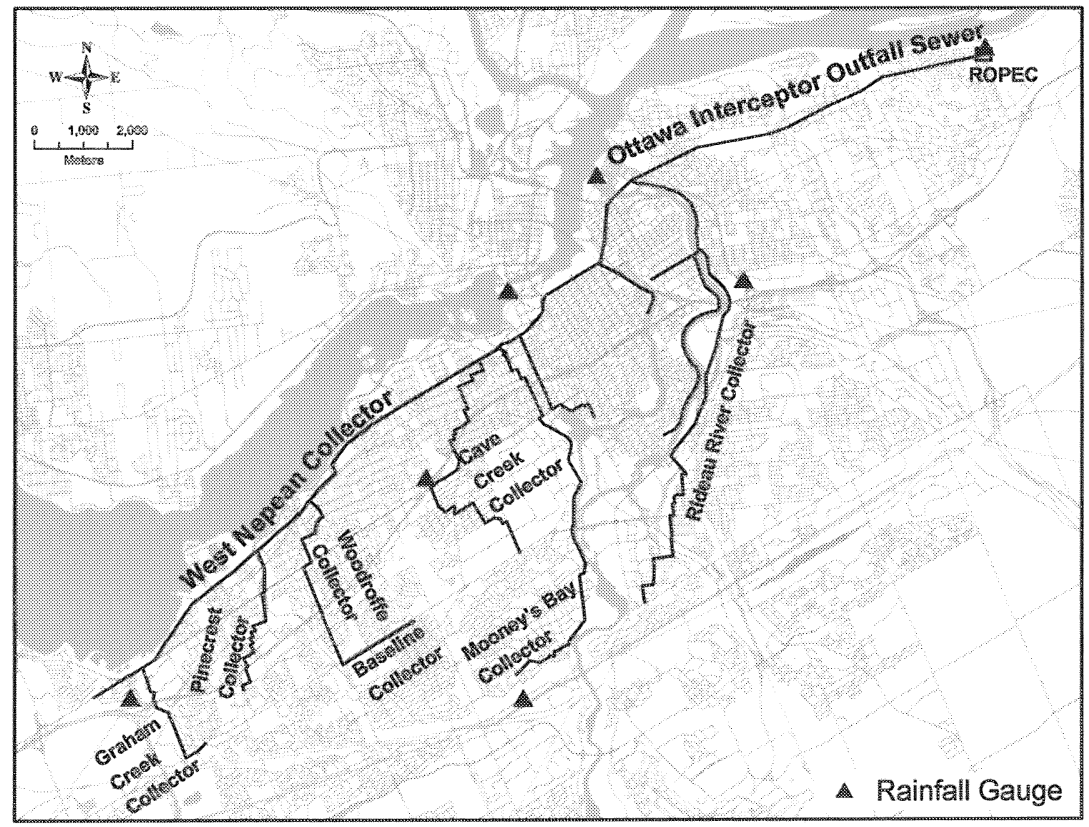

Figure 11.1 City of Ottawa sanitary sewer system.

committed to meeting the requirements of MOE CSO Control Policy F-5-5 which lists the following minimum CSO controls:

- eliminate CSOs during dry weather periods except under emergency conditions;

- establish and implement pollution prevention programs that focus on pollutant reduction activities at the sources;

- establish and implement proper operation and regular inspection and maintenance programs for the combined sewer system in order to ensure continued proper system operation;

- establish and implement a floatables control program to control coarse solids and floatables materials;

- maximize the use of the collection system for the storage of wet weather flow which are conveyed to the Sewage Treatment Plant for treatment when capacity is available;

- maximize the flow to the Sewage Treatment Plant for the treatment of wet weather flows; and,

- during a seven month period commencing within fifteen days of April 1, capture and treat for an average year all the dry weather 
flow plus $90 \%$ of the volume resulting from wet weather flow that is above the dry weather flow. This criteria is to be applied on a regulator or system wide basis.

The City of Ottawa has addressed most of these requirements through a wide variety of studies and programs. The Central Storage Facility Class Environmental Assessment (Class EA) study was undertaken to address the last criteria and selected a central storage tunnel facility as the preferred alternative.

Following the completion of the Class EA study, the City and the former Region of Ottawa-Carleton began the Somerset Wastewater Storage Facility Project, which included the development of a refined conceptual design for the central storage tunnel facility and subsequent preliminary and detailed design phases.

\subsection{Project Model}

At the outset of the Somerset Wastewater Storage Facility Project, the need to address to a number of outstanding issues was raised. These issues had a direct bearing on the modeling tools used in the Class EA study and included the following:

- The City of Ottawa had completed many sewer separation projects and was committed to completing sewer separation for the majority of the combined system by the year 2004;

- The City of Ottawa is proceeding with the design and construction of three flow diversions within the service area of the West Nepean Collector which will divert wet weather flows during large wet weather events to the South Ottawa Collector;

- An existing XP-SWMM model of the collection system, used in the analysis of alternatives in the Class EA study, had been calibrated with data collected in 1988. The former Region and City had both undertaken significant flow monitoring programs since the completion of the EA study which would allow the model calibration to be revisited; and,

- The need to review the existing model representation of key hydraulic elements including regulator and overflow structures.

To resolve these issues, it was decided that a refined Project Model would be developed. The refinements included updating the model calibration, the selection of hydrologic model parameters to represent areas which would undergo partial separation by the year 2004, updates to future flow projections 
based on the 1997 Wastewater Master Plan, and the selection of a typical rainfall year. Figure 11.2 presents an overview of the model refinements and planned model application.

The Project Model was then to be utilized to confirm the required size and operation of the Somerset Wastewater Storage Facility. A number of model scenarios were developed to represent design variations being considered by the project team. These variations included the construction of a connection between the Somerset Wastewater Storage Facility and the West Nepean Collector. The West Nepean Collector receives significant wet weather flows despite the fact that the tributary area is largely separated.

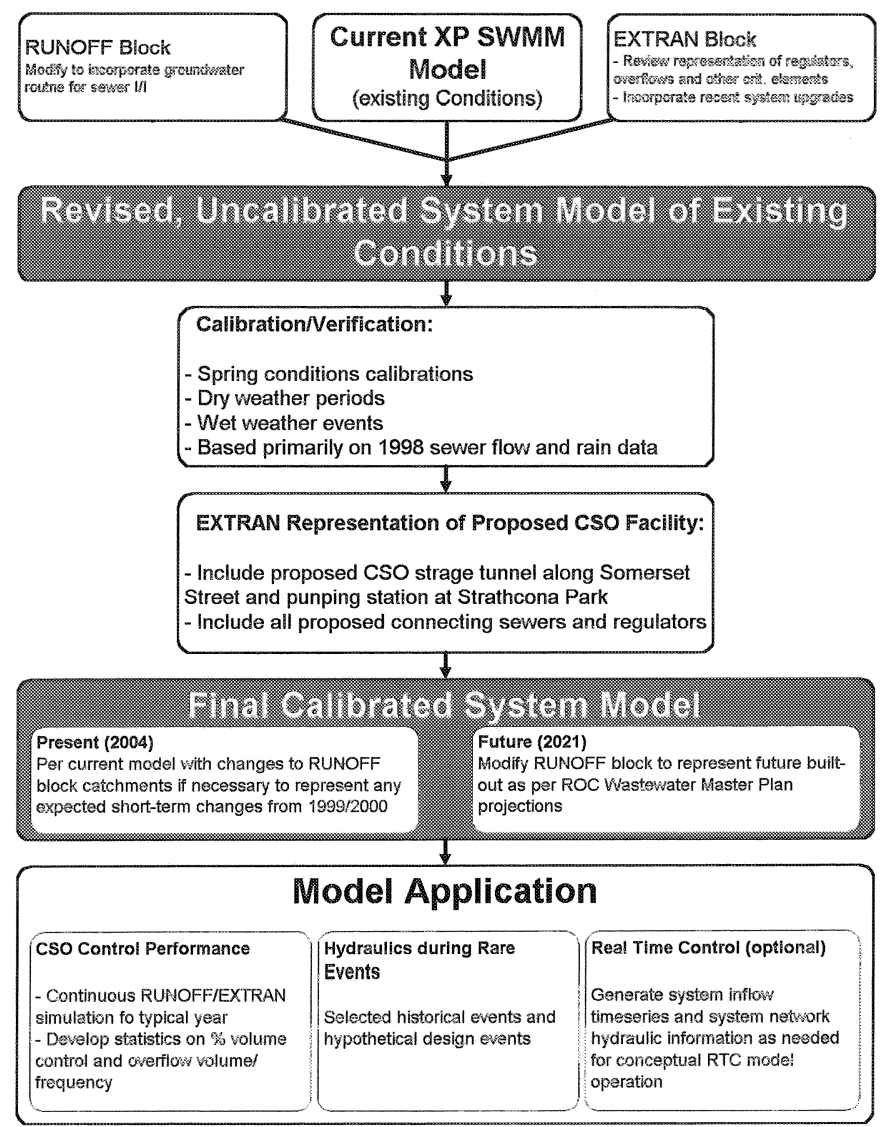

Figure 11.2 Development and application of the project model. 
Model refinements included the following:

- updates to the physical structure of the model to represent a number of projects that the City and the former Region have undertaken since 1996;

- the development of hydrologic model parameters to represent newly partially separated areas; and

- an updated model calibration using flow data collected at a total of fifteen sites and rainfall data collected at a total of seven sites.

\subsection{Project Model Calibration}

To ensure a consistent Project Model calibration, a calibration procedure was developed. The procedure was designed to enhance the ability of the Project Model to represent existing hydrologic and hydraulic conditions. The calibration methodology included:

1. All model calibrations were completed using EXTRAN to account for any hydraulic limitations in the local collection systems.

2. Dry weather flows and dry weather flow diurnal patterns were input in the Project Model. Calibrations were completed using the total recorded flow at each location and not just the wet weather component.

3. Prior to beginning the model calibrations for each flow monitoring location, a review of the flow data was undertaken to determine the nature of the wet weather response. A review of catchment characteristics was also undertaken. Where a long infiltration response was identified, model calibrations were completed using the RUNOFF groundwater routine. Where no long infiltration response could be identified, model calibrations were completed without the groundwater routine.

4. Model calibrations were completed using rainfall data from the nearest rain gauge with available data.

As part of the model calibration procedure, initial values for all parameters were selected. Some of these values were adjusted to calibrate the model. In general, catchment percent imperviousness, width, selected infiltration parameters and selected groundwater parameters were adjusted to facilitate model calibration. Table 11.1 presents the initial parameters selected and identifies calibration parameters that were adjusted to calibrate the model. 
Table 11.1 Initial model parameter settings.

\begin{tabular}{|c|c|c|}
\hline Parameter & $\begin{array}{l}\text { Initial } \\
\text { Value }\end{array}$ & Type of Parameter \\
\hline Area & & Fixed value \\
\hline Combined Area Percent Imperviousness (\%) & 25 & Calibration parameter \\
\hline P. Sep. Percent Imperviousness (\%) & 1.5 & Calibration parameter \\
\hline Sep. Percent Imperviousness (\%) & 0.5 & Calibration parameter \\
\hline Combined Catchment Width (m) & 40 & Calibration parameter \\
\hline P. Sep. Catchment Width (m) & 160 & Calibration parameter \\
\hline Sep. Catchment Width (m) & 500 & Calibration parameter \\
\hline Catchment Slope $(\%)$ & 1.0 & Calibration parameter \\
\hline Impervious Area Depression Storage (mm) & 2.0 & Calibration parameter \\
\hline Pervious Area Depression Storage (mm) & 3.0 & Calibration parameter \\
\hline Impervious Area Mannings n & 0.015 & Calibration parameter \\
\hline Pervious Area Mannings n & 0.35 & Calibration parameter \\
\hline Zero Detention & 0 & Calibration parameter \\
\hline Maximum Infiltration Rate $(\mathrm{mm} / \mathrm{h})$ & 38.1 & Calibration parameter \\
\hline Minimum Infiltration Rate $(\mathrm{mm} / \mathrm{h})$ & 7.62 & Calibration parameter \\
\hline Infiltration Decay Rate (1/s) & 0.0015 & Fixed value \\
\hline Groundwater upper Zone Depth (m) & 5.0 & Calibration parameter \\
\hline Lower Zone Depth $(\mathrm{m})$ & 5.0 & Calibration parameter \\
\hline Lower Zone Beneath Channel Depth (m) & 0.2 & Calibration parameter \\
\hline Channel Depth $(\mathrm{m})$ & 0.2 & Calibration parameter \\
\hline Wilting Point & 0.15 & Fixed value \\
\hline Field Capacity & 0.33 & Fixed value \\
\hline Fraction of ET in Upper Zone & 0.90 & Fixed value \\
\hline Saturated Hydraulic Conductivity & 2.0 & Fixed value \\
\hline Porosity & 0.4 & Fixed value \\
\hline Curve Fitting parameter & 10 & Calibration parameter \\
\hline Initial Upper Zone Moisture & 0.33 & Fixed value \\
\hline Coefficient of Unquantified Losses & 0 & Fixed value \\
\hline Area Slope of Tension & 0 & Fixed value \\
\hline Groundwater Flow Coefficient & 0.0025 & Calibration parameter \\
\hline Groundwater Flow Exponent & 0.95 & Calibration parameter \\
\hline Channel Water Influence Coefficient & 0 & Fixed value \\
\hline Channel Water Influence Exponent & 1.0 & Fixed value \\
\hline Groundwater/Channel Water Coefficient & 0 & Fixed value \\
\hline
\end{tabular}

Model calibrations were undertaken using flow data at fifteen flow monitoring locations and seven rain gauges shown in Figure 11.1. Where possible, a minimum of three events were used to calibrate the model.

Figures 11.3 and 11.4 present the results of model calibrations. Figure 11.3 presents the comparison of modeled and measured peak flows for all of the model calibration undertaken. Examination of Figure 11.3 shows that modeled and measured peak flows were within a $15 \%$ envelope for 26 of 39 model calibrations. Examination of Figure 11.4 shows that modeled and measured event volumes were within a $15 \%$ envelope for 32 of 39 model calibrations. However, at several locations, only limited model calibrations were undertaken due to a lack of suitable data to confirm model parameters. 


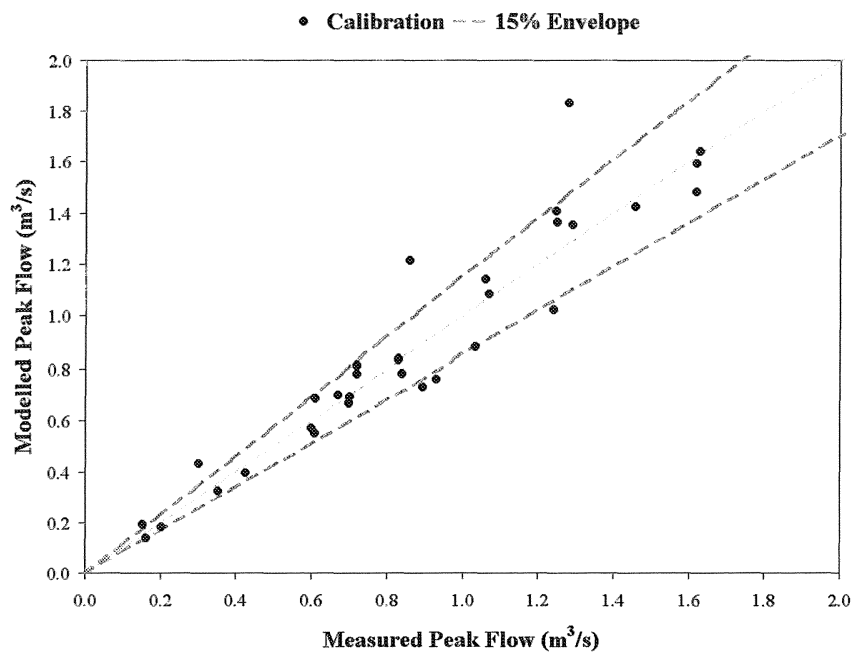

Figure 11.3 Comparison of modeled and measured peak flows.

In general, measured and modeled peaks flows and event volumes matched well. The exception to this occurred in the West Nepean Collector where modeled and measured flows did not match well. A review of the flow data recorded at the flow monitoring location indicated wet weather responses

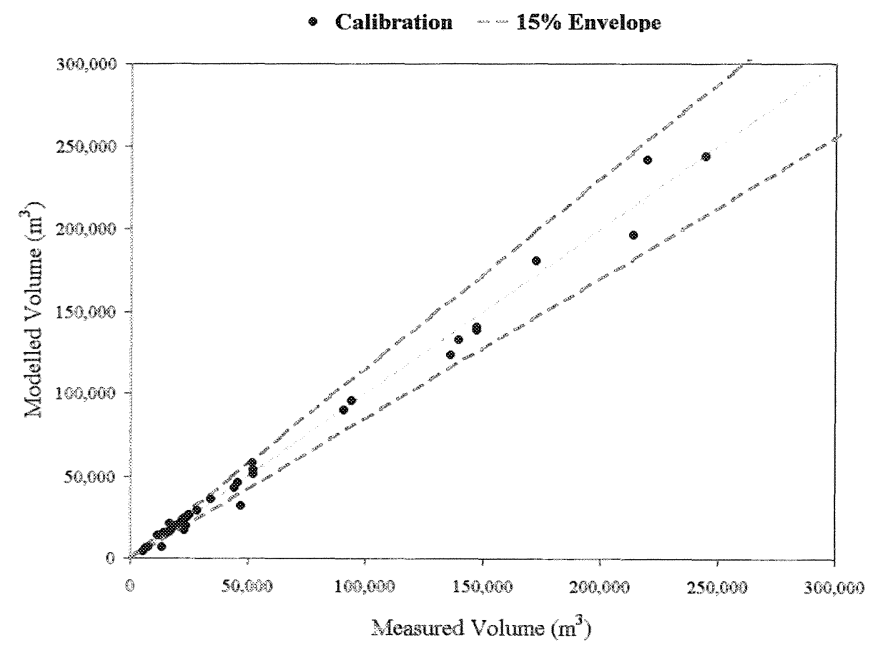

Figure 11.4 Comparison of modeled and measured event volumes. 
when no rainfall was recorded at three rain gauges. Also, a minimal response was evident in the flow data to short, high-intensity rainfall events recorded at some of the rain gauges in and around the drainage area. Additional model calibration was therefore undertaken for the West Nepean Collector sewershed area to confirm model parameters using the virtual rain gauge information described in the following section.

\subsection{Radar Precipitation Data}

The radar technology detects raindrops and clouds much the same way that it detects airplanes. The radar antenna emits a pulse of microwave energy, which is scattered by rain or snow or ice particles. Some of the energy is reflected back to the radar detector as an "echo". The radar system is able to display the location of the "echo" based on the time it takes between sending the signal and receiving the reflected signal back again. The intensity of the echo is based on the concentration of rain or snow (Environment Canada Web Site). Environment Canada presently maintains 22 radar stations, which cover 90 to $95 \%$ of the population in Canada. Each radar station has a detection area of $240 \mathrm{~km}$ in radius.

The weather radar information from Environment Canada was utilized to develop the virtual rain gauge precipitation information. RADHYPS, a Canadian company specializing in water resources products and services that are based on radar hydrology technologies performed this task. The company's RainScan product includes high-resolution distributions of precipitation accumulations at spatial resolutions of $1 \mathrm{~km}^{2}$ and temporal intervals of $5 \mathrm{~min}$. The radar data for each storm event is organized as a series of matrices. Each matrix encompasses data over the territory of interest and is composed of cells representing the total precipitation over a space of $1 \mathrm{~km}^{2}$ and for a time interval of $5 \mathrm{~min}$.

The radar precipitation data was adjusted with available rain gauge information to increase the ground catch estimate accuracy. Rain gauge data was utilized to derive temporally varying corrective factors. This was accomplished by comparing variations in rain gauge and radar precipitation volumes for a set time period, typically 30 minutes. Consequently, the computed corrective factors were applied to the entire radar data in order to obtain the best ground catch rainfall intensity estimates. RADHYPS uses several weather radar data corrective methods, which range from simple linear spatio-temporal averaging techniques to more complex point influence zones considering the location of each rain gage within a network. 
The virtual rainfall gauge data produced for a $1 \mathrm{~km}^{2}$ grid was averaged over the model sub-catchments. Figure 11.5 shows the extent of rainfall spatial variability, as derived from the radar precipitation information, for catchments in the Cave Creek Collector system for three events in 1999. During the May 24, 1999 event, the lowest rainfall depth in the Cave Creek Collector drainage area was $16.8 \mathrm{~mm}$ (catchment cc05000), while the largest depth of $22.7 \mathrm{~mm}$ occurred over the sub-catchment cc07300, indicating a difference of $26 \%$. Similarly, the difference between the largest and smallest rainfall volume in the Cave Creek Collector drainage area was $44 \%$ and $31 \%$ during the events of June 12, 1999 and July 9, 1999, respectively.

The virtual rain gauge precipitation data was compiled into a single precipitation (.rin) data file for use in the Project Model. Each virtual rain gauge station was assigned a name corresponding to the sub-catchment to which the rainfall was applied. The resulting precipitation data file contained data for a total of 87 virtual rain gauges.

- May 24, 1999 Event - June 12, 1999 Event 곴-July 9, 1999 Event

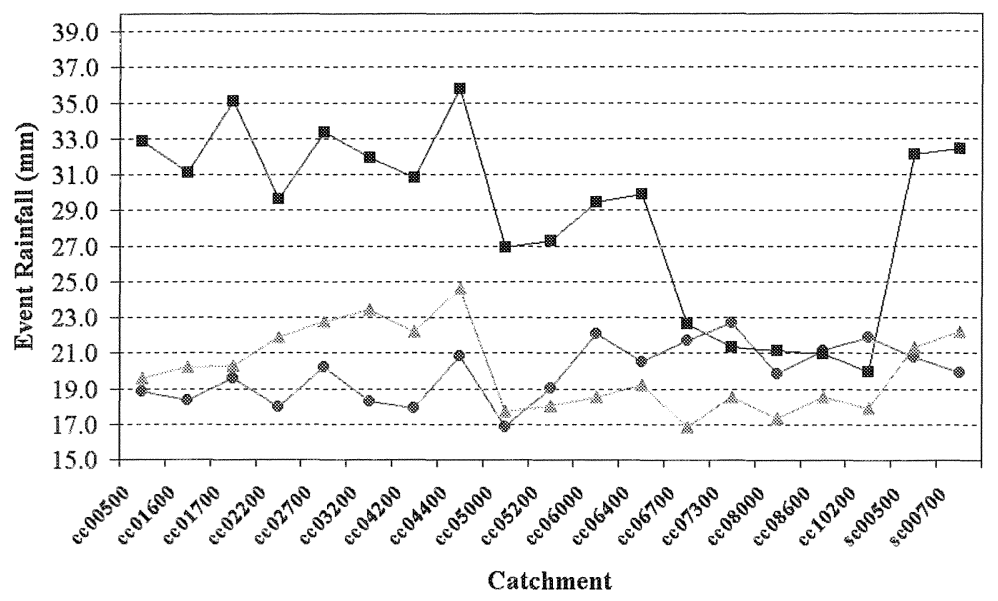

Figure 11.5 Cave Creek Collector spatial variability of rainfall.

\subsection{Final Model Calibrations}

The rainfall data utlized in the final model calibrations consisted of 5-min rainfall data for 1998 and 1999 generated for each sub-catchment in the Project Model. This data was input directly into the model and utilized to refine the model of 
Pinecrest, Woodroffe, West Nepean, Mooney's Bay, and Cave Creek Collectors. The runoff and groundwater parameters that resulted from the previous calibration exercise were refined using this additional data.

Additional flow monitoring data was also used in the final model calibrations. Data from the West Nepean Collector at Wylie and Woodroffe Collector, shown in Figure 11.6, were used to conduct a more detailed model calibration in a systematic manner, starting with the upper-most portions of the collection system. Results of calibrations of individual trunk drainage areas follow.

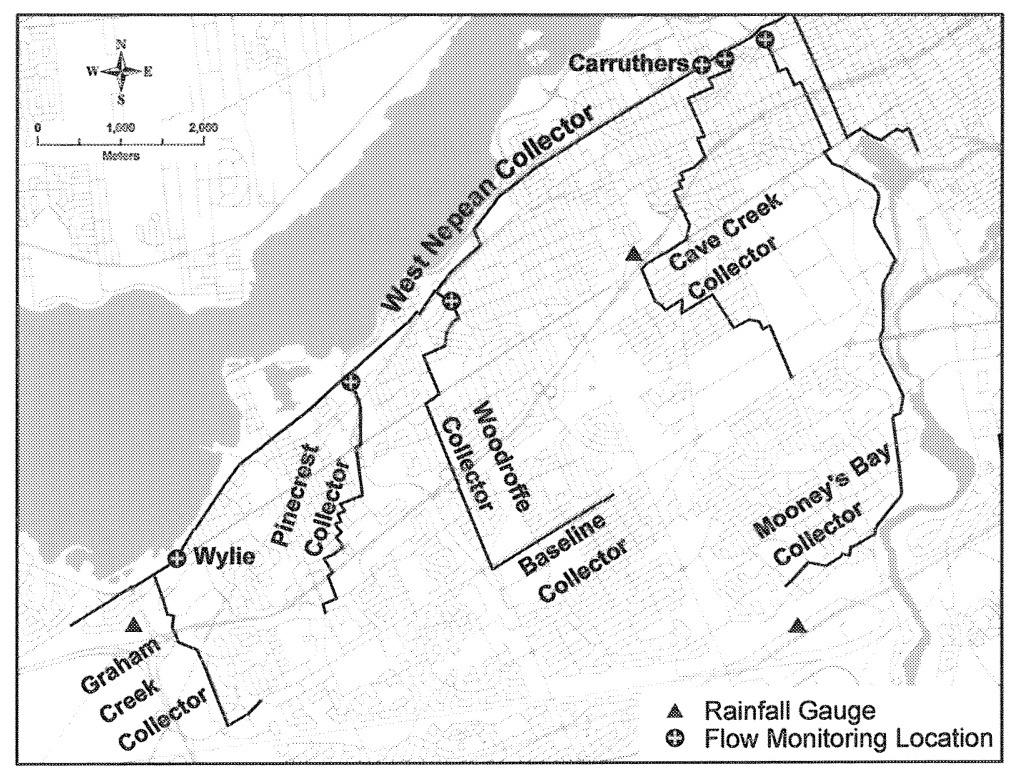

Figure 11.6 Flow monitoring sites - final model calibrations.

\section{Pinecrest Collector}

Model calibrations for the Pinecrest Collector were completed with flow and rainfall data for a total of five events. A review of flow data collected in the Pinecrest Collector revealed that peak flow response of the area was moderate, and the dry weather flows following the rainfall event were elevated slightly for a period of about two to five days following the event. This type of response is typical of a slow infiltration response. The groundwater modeling routine was utilized to capture this response.

The model calibration procedure focused on adjustments to the infiltration, percolation and groundwater outflow parameters. Specifically, the percolation curve fitting parameter and the groundwater outflow coefficient and 
exponent, were all adjusted to obtain a good match between measured and modeled results. Table 11.2 presents the results of the calibration. The rainfall volumes shown in Table 11.2 represent area weighted rainfall volumes calculated using the radar rainfall data for the Pinecrest Collector catchments.

The calibration events had rainfall volumes ranging from $18.5 \mathrm{~mm}$ to 42.7 $\mathrm{mm}$. A review of the calibration curves indicated that the model reasonably computes hydrograph shape, peak flows and event volumes.

Table 11.2 Pinecrest Collector calibration results.

\begin{tabular}{cccccc} 
Event Date & $\begin{array}{c}\text { Rainfall } \\
\text { Volume } \\
\text { (mm) }\end{array}$ & \multicolumn{2}{c}{ Peak Flows (L/s) } & Event Volumes $\left(\mathrm{m}^{3}\right)$ \\
\cline { 3 - 6 } May 8-14, 1999 & 18.5 & 220 & 190 & 67,000 & 60,400 \\
July 24-28, 1999 & 19.2 & 260 & 250 & 40,800 & 40,300 \\
Sept. 20-24, 1999 & 30.0 & 210 & 260 & 39,200 & 41,400 \\
Oct. 12-19, 1999 & 31.1 & 170 & 160 & 65,600 & 64,700 \\
Nov. 2-9, 1999 & 42.7 & 230 & 290 & 69,800 & 67,500 \\
\hline
\end{tabular}

\section{West Nepean Collector at Wylie}

Model calibrations for the West Nepean Collector at Wylie were completed with flow and rainfall data for a total of four events. As with the Pinecrest Collector, the model calibration procedure focused on adjustments to the infiltration, percolation and groundwater outflow parameters. Table 11.3 presents the calibration results. The rainfall volumes shown in Table 11.3 represent area weighted rainfall volumes calculated using the radar precipitation data for the catchments upstream of Wylie.

The calibration events had rainfall volumes ranging from $19.3 \mathrm{~mm}$ to 40.2 $\mathrm{mm}$. A review of the calibration curves indicated that the model reasonably computes hydrograph shape, peak flows and event volumes.

Table 11.3 West Nepean Collector at Wylie calibration results.

\begin{tabular}{lcccccc}
\hline \multirow{2}{*}{ Event Date } & \begin{tabular}{c} 
Rainfall \\
Volume \\
\cline { 5 - 7 }
\end{tabular} & \multicolumn{2}{c}{ Peak Flows $(\mathrm{L} / \mathrm{s})$} & \multicolumn{2}{c}{ Event Volumes $\left(\mathrm{m}^{3}\right)$} \\
\hline May $8-14,1999$ & 19.3 & 210 & 240 & 57,600 & 61,500 \\
July 24-28, 1999 & 40.1 & 210 & 210 & 55,400 & 59,800 \\
Oct. 12-19, 1999 & 28.6 & 160 & 140 & 59,400 & 59,000 \\
Nov. 2-9, 1999 & 40.2 & 190 & 200 & 65,800 & 66,800 \\
\hline
\end{tabular}




\section{Woodroffe Collector}

Model calibrations for the Woodroffe Collector were completed with flow and rainfall data for a total of three events. A review of flow data collected in the Woodroffe Collector revealed that peak flow response of the area was relatively small, and the dry weather flows following the rainfall event were elevated for a period of about four to seven days following the event. Again, the groundwater modeling routine was utilized to capture this response. Table 11.4 presents the results of the calibration. The rainfall volumes shown in Table 11.4 represent area weighted rainfall volumes calculated using the radar precipitation data for each catchment in the Woodroffe Collector.

The calibration events had rainfall volumes ranging from $12.4 \mathrm{~mm}$ to 24.8 $\mathrm{mm}$. A review of the calibration curves indicated that the model reasonably computes hydrograph shape, peak flows and event volumes.

Table 11.4 Woodroffe Collector calibration results.

$\begin{array}{lccccc}\text { Event Date } & \begin{array}{c}\text { Rainfall } \\ \text { Volume } \\ \text { (mm) }\end{array} & \text { Measured } & \text { Modeled } & \text { Measured } & \text { Modeled } \\ \text { May 7-17, 1999 } & 12.4 & 200 & 240 & 107,000 & 110,900 \\ \text { May 24-Jun 2, 1999 } & 20.5 & 210 & 200 & 87,800 & 96,400 \\ \text { June 2-13, 1999 } & 24.8 & 240 & 240 & 115,100 & 117,900 \\ & & & & & \end{array}$

\section{West Nepean Collector at Carruthers}

Model calibrations for the West Nepean Collector at Carruthers were completed with flow and rainfall data for a total of five events. This section of the model was calibrated after calibrating the Pinecrest Collector, the Woodroffe Collector, and the West Nepean Collector at Wylie, since these three systems are all upstream of Carruthers. A review of flow data collected at Carruthers revealed that peak flow response of the area was low, and the dry weather flows following the rainfall event were elevated for a period of about four to seven days following the event. This type of response is typical of a slow infiltration response. The groundwater modeling routine was again utilized to capture this response. Table 11.5 presents the results of the calibration. The rainfall volumes shown in Table 11.5 represent area weighted rainfall volumes calculated using the radar rainfall data for each catchment in the West Nepean Collector.

The calibration events had rainfall volumes ranging from $19.7 \mathrm{~mm}$ to 41.1 $\mathrm{mm}$. A review of the calibration curves indicated that the model reasonably computes hydrograph shape, peak flows and event volumes. 
Table 11.5 West Nepean Collector at Carruthers calibration results.

\begin{tabular}{ccccccc}
\hline \multirow{2}{*}{ Event Date } & $\begin{array}{c}\text { Rainfall } \\
\text { Volume }\end{array}$ & \multicolumn{2}{c}{ Peak Flows (L/s) } & \multicolumn{2}{c}{ Event Volumes $\left(\mathrm{m}^{3}\right)$} \\
\cline { 5 - 6 } & $(\mathrm{mm})$ & Measured & Modeled & Measured & Modeled \\
\cline { 4 - 6 } May 8-12, 1999 & 21.9 & 1,060 & 1,010 & 257,700 & 256,700 \\
May 24-28, 1999 & 19.7 & 840 & 790 & 187,100 & 195,100 \\
Sept 20-25, 1999 & 31.1 & 1,140 & 1,260 & 288,300 & 298,000 \\
Oct 12-19, 1999 & 30.9 & 990 & 840 & 408,200 & 396,800 \\
Nov 2-11, 1999 & 41.1 & 1290 & 1160 & 555,900 & 524,500 \\
\hline
\end{tabular}

\section{Mooney's Bay Collector}

Model calibrations for the Mooney's Bay Collector were completed with flow and rainfall data for a total of three events. This area is largely partiallyseparated, and a review of the flow data showed a very small infiltration response. Calibration for this system therefore focussed on adjustments to the percent imperviousness and catchment width to achieve a good match between modeled and measured flows. The groundwater routine was then used to slightly extend the tail of the runoff hydrograph. Table 11.6 presents the results of the calibration. The rainfall volumes shown in Table 11.6 represent area weighted rainfall volumes calculated using the radar rainfall data for each catchment in the Mooney's Bay Collector.

The calibration events had rainfall volumes ranging from $19.2 \mathrm{~mm}$ to $33.8 \mathrm{~mm}$. A review of the calibration curves indicated that the model reasonably computes hydrograph shape, peak flows and event volumes.

Table 11.6 Mooney's Bay Collector calibration results.

\begin{tabular}{lccccc}
\hline \multirow{2}{*}{ Event Date } & \multirow{2}{*}{$\begin{array}{c}\text { Rainfall } \\
\text { Volume }\end{array}$} & \multicolumn{2}{c}{ Peak Flows $(\mathrm{L} / \mathrm{s})$} & \multicolumn{2}{c}{ Event Volumes $\left(\mathrm{m}^{3}\right)$} \\
\cline { 3 - 6 } & $(\mathrm{mm})$ & Measured & Modeled & Measured & Modeled \\
\hline May 24-26, 1999 & 19.2 & 420 & 610 & 27,900 & 26,100 \\
June 1-4, 1999 & 33.8 & 1,310 & 1,320 & 48,300 & 48,900 \\
July 9-11, 1999 & 21.1 & 660 & 630 & 29,800 & 28,300 \\
\hline
\end{tabular}

\section{Cave Creek Collector}

Model calibrations for the Cave Creek Collector were completed with flow and rainfall data for a total of four events. This area is largely partially-separated and combined, and a review of the flow data showed a very small infiltration response. Calibration for this system therefore focussed on adjustments to the 
percent imperviousness and catchment width to achieve a good match between modeled and measured flows. The groundwater routine was then used to slightly extend the tail of the runoff hydrograph. Table 11.7 presents the results of the calibration. The rainfall volumes shown in Table 11.7 represent area weighted rainfall volumes calculated using the radar rainfall data for each catchment in the Cave Creek Collector.

The calibration events had rainfall volumes ranging from $19.4 \mathrm{~mm}$ to $44.3 \mathrm{~mm}$. A review of the calibration curves indicated that the model reasonably computes hydrograph shape, peak flows and event volumes.

Table 11.7 Cave Creek Collector calibration results.

\begin{tabular}{lcccccc}
\multirow{2}{*}{ Event Date } & \multirow{2}{*}{$\begin{array}{c}\text { Rainfall } \\
\text { Volume }\end{array}$} & & \multicolumn{2}{c}{ Peak Flows (L/s) } & \multicolumn{2}{c}{ Event Volumes $\left(\mathrm{m}^{3}\right)$} \\
\cline { 3 - 6 } & $(\mathrm{mm})$ & Measured & Modeled & Measured & Modeled \\
\cline { 3 - 6 } May 24-26, 1999 & 19.4 & 1,260 & 1,540 & 59,200 & 60,300 \\
June 1-4, 1999 & 34.4 & 1,960 & 2,540 & 107,300 & 109,600 \\
July 5-9, 1999 & 44.3 & 1,750 & 1,550 & 162,700 & 160,600 \\
July 23-26, 1999 & 38.8 & 1,690 & 1,610 & 86,500 & 88,600 \\
\hline
\end{tabular}

Figure 11.7 presents the comparison of modeled and measured peak flows for all of the final model calibration undertaken. Examination of Figure 11.7 shows that measured and modeled peak flows were within the $15 \%$ envelope for 17 out of 24 events. These results indicate that the refined model is capable of predicting peak flows in the West Nepean, Cave Creek and Mooney's Bay Collectors within a reasonable range of error.

Figure 11.8 presents the comparison of modeled and measured volumes for the final model calibration undertaken. Examination of Figure 11.8 shows that measured and modeled event volumes were within a $15 \%$ envelope for all 24 model calibrations. These results indicate that the refined XP-SWMM model is capable of adequately predicting event volumes.

\subsection{Summary and Conclusions}

The City of Ottawa's sanitary sewer system services the older portions of the city and also conveys flows from the West Nepean Collector. The collection system currently accepts all dry weather flows, and also intercepts an estimated $82 \%$ of wet weather flows. As a part of the City's commitment to meet the MOE CSO Control Policies, an underground storage facility is being considered. 


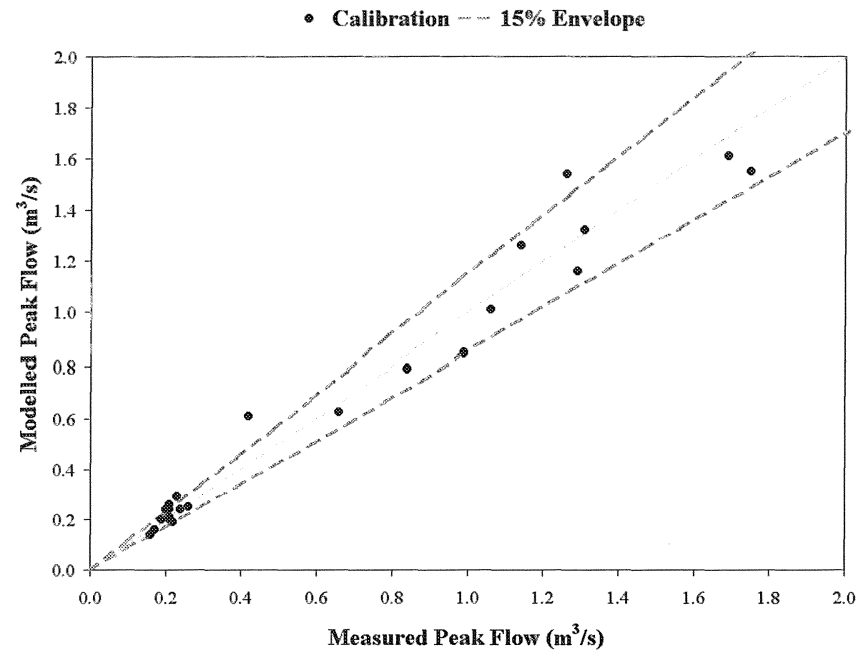

Figure 11.7 Comparison of measured and modeled peak flows - final calibrations.

The conceptual design of the Somerset Wastewater Storage Facility necessitated the development of a Project Model of the City's collection system. The initial calibrations of the Project Model, completed using point rainfall estimates from rain gauges did not produce adequate results for the West Nepean sewershed, and were adequate for the remainder of the system. To

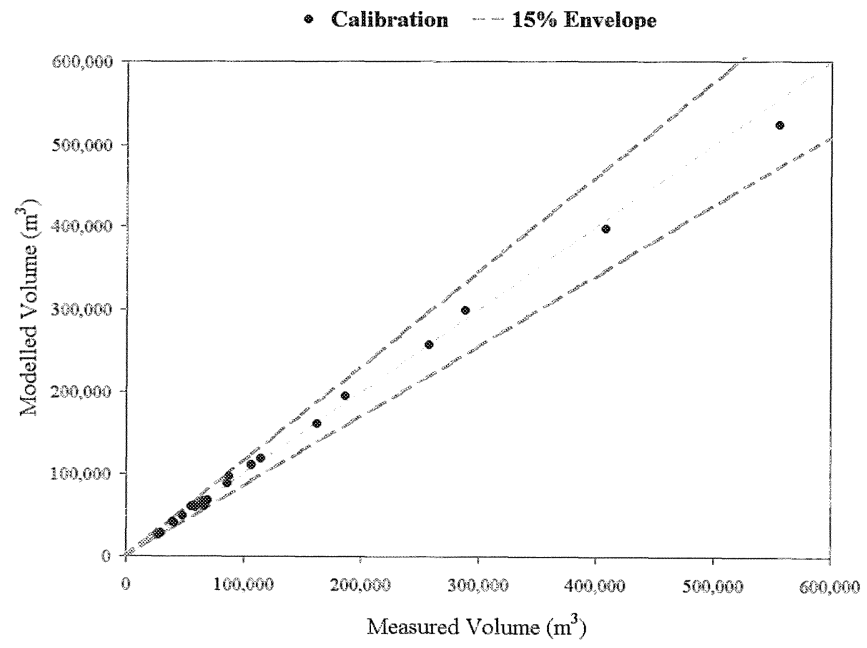

Figure 11.8 Comparison of measured and modeled volumes - final calibrations. 
assist in the calibration of the West Nepean portion of the Project Model, rainfall data was developed for a virtual rain gauge network. The virtual rain gauge network provided 5-min rainfall volume estimates for each $1 \mathrm{~km}^{2}$ of the drainage area, utilizing data from the existing rain gauges and the weather radar information.

Model calibration was performed utilizing virtual rain gauge data averaged of the Project Model sub-catchment areas in the West Nepean sewershed. Radar precipitation information provided accurate rainfall estimates over the large drainage area that enabled the successful model calibration. As a result of the calibration efforts, better prediction of inflows to Somerset Wastewater Storage Facility will be achieved, which will improve confidence in its sizing and the development of the optimal operating strategy.

\section{References}

Ball, J.E., 1994, The influence of Storm Temporal Patterns on Catchment Response, Journal of Hydrology, No. 158, pp. 285-303.

Environment Canada Web Site, http://www.ec.gc.ca/press/000816_b_e.htm, Accessed on September 9, 2002.

Faures, J., D.C. Goodrich, D.A. Woolhiser, and S. Sorooshian, 1995, Impact of SmallScale Spatial Rainfall Variability on Runoff Modelling, Journal of Hydrology, No. 173, pp. 309-326.

Koren V.I., B.D. Finnerty, J.C. Schaake, M.B. Smith, D.J. Seo, and Q.Y. Duan, 1999, Scale dependencies of hydrologic models to spatial variability of precipitation, Journal of Hydrology. No. 217, pp. 285-302.

Ogden, F.L., and P.Y. Julien, 1993, Runoff Sensitivity to Temporal and Spatial Rainfall Variability at Runoff Plane and Small Basin Scale, Water Resources Research, Vol. 29, pp. 589-2597.

Schilling, W., 1984, Effect of Spatial Rainfall Distribution on Sewer Flows, Water Science and Technology, Vol. 16, pp. 177-188. 